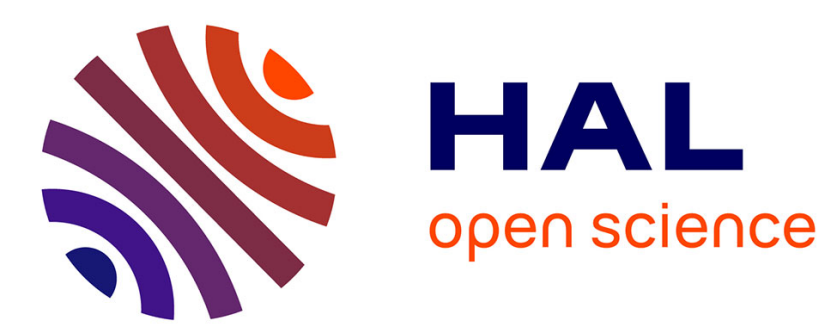

\title{
Digital technologies to teach and learn mathematics: Context and re-contextualization
} Jean-Baptiste Lagrange, Chronis Kynigos

\section{To cite this version:}

Jean-Baptiste Lagrange, Chronis Kynigos. Digital technologies to teach and learn mathematics: Context and re-contextualization. Educational Studies in Mathematics, 2014, 85 (3), pp.381 - 403. 10.1007/s10649-013-9525-z . hal-01740449

\section{HAL Id: hal-01740449 \\ https://hal.science/hal-01740449}

Submitted on 22 Mar 2018

HAL is a multi-disciplinary open access archive for the deposit and dissemination of scientific research documents, whether they are published or not. The documents may come from teaching and research institutions in France or abroad, or from public or private research centers.
L'archive ouverte pluridisciplinaire HAL, est destinée au dépôt et à la diffusion de documents scientifiques de niveau recherche, publiés ou non, émanant des établissements d'enseignement et de recherche français ou étrangers, des laboratoires publics ou privés. 
Published in EducStudMath(2014) 85:381-403

http://rd.springer.com/article/10.1007\%2Fs10649-013-9525-z

DOI10.1007/s10649-013-9525-z

\title{
Digital Technologies to Teach and Learn Mathematics; context and re-contextualization
}

\author{
JEAN-BAPTISTE LAGRANGE, CHRONIS KYNIGOS
}

\begin{abstract}
The central assumption of this paper is that, especially in the field of digital technologies to teach and learn mathematics, the influence of the context in which research is carried out has not been given enough attention, so that research outcomes cannot be really useful outside this context. We base our discussion on the work of a group of European teams carrying out research with a special methodology of "cross-studies" and carrying out "cross-analyses" of particular studies. A context for a research study is described as a dynamic construction by researchers, connecting relevant contextual characteristics in the settings (empirical and academic) where research activity takes place and helping to gain insight from the outcomes of the study. Analyzing the design of two "Didactical Digital Artefacts", and the associated cross-studies involving teams of three countries, we identify more or less conscious influences of characteristics in the researchers' contexts upon research outcomes. Cross-studies and cross-analysis help to go further by making researchers more aware of their context and of its characteristics. It also helps researchers to "re-contextualize", that is to say to identify new contextual characteristics in the settings they are acting in, in order to gain insight from research outcomes that emerged in other contexts.
\end{abstract}

Keywords: Digital Technologies, cross-study, cross-analysis, context, empirical context, academic context, Casyopée, Cruislet

\section{Introduction}

Over the last two decades, substantial international research into the use of digital technologies in the teaching and learning of mathematics has yielded powerful results. At the same time educators and software developers in many countries across the world have attempted to develop and introduce technological artefacts into classrooms with the aim of improving mathematics education. In spite of the massive investment of resources, both financial and human, in pursuit of this aim, impact on the reality of school practices has been limited. How are we to understand, explain and attempt to overcome this disjunction between the impressive research knowledge acquired, the implementation efforts, and the impact it has on actual practices? The central assumption of this paper is that the influence of the contexts from which research in the field of digital technologies to teach and learn mathematics has emerged has not been given enough attention so that research outcomes cannot be really insightful outside each context respectively. We base our discussion on the work of an international group of six European research teams within a multi-organizational project titled 'Representing Mathematics' (ReMath project) which was carried out from 2005 to 2009. As explained in the introductory paper of this special issue (Kynigos \& Lagrange, this volume), the general aim of the project was to forge connections amongst diverse and hitherto fragmented research approaches to teaching and learning mathematics with digital media. One of the key foci of the project was precisely to better understand what makes the context of a 
research study and to seek a method in order to make research outcomes obtained in a given context insightful in another context.

A distinct feature of the ReMath project was that each of the teams engaged in the whole cycle of design and development of an innovative software, named Dynamic Digital Artifact (DDA) and carried out empirical research involving its use in realistic classroom situations. The choice of whole cycle engagement of all teams was motivated by the need to work on concrete boundary objects (Kynigos \& Psycharis, 2009) deeply involving contextual characteristics. Part of the study was based on cross-experimentation of DDAs, a method already tried in the TELMA pilot study (Bottino \& Kynigos, 2009). We knew that crossexperimenting the DDAs would bring forth contextual characteristics influencing the DDAs' design and the implementation of scenario of uses, but also that this identification of contextual characteristics could not provide the deep understanding of the contexts that was aimed at. Then we chose to complete cross-experimentation by cross-analysis of cases that issued from the experimentation: each team engaged both in research with another team's DDA and in analyzing another team's data through its own perspective and framework. The central method is then cross-studies, that is to say cross-experimentation, completed by crosscase analysis. Here two cross-studies are considered involving two DDAs and three teams from three different European countries.

\section{The mediating role of context}

As Healy and Sacristan (this volume) say,

We might define context as the set of the "interrelated conditions in which something exists or occurs", but this (definition) does not emphasise the relationships between the context and the something-that is, the mediating role of context and can be operationalized in a multitude of manners,

We seek below to define more precisely the "interrelated conditions" we are considering. Here we try to look at the mediating role of context, drawing from math education research that has been concerned by how socio-cultural contexts impinge on students' cognitive processes. From the study of street mathematics (Nunes, Schliemann \& Carraher, 1993), context was indirectly recognized as the ways in which learning is shaped by the situation it takes place in (Lave, 1998). Cognitive processes actually cannot be though of independently of a context (Kynigos \& Psycharis, ibid). Van Oers (1998, p.175) describes how context necessarily mediates cognition.

Context-generally spoken - provides for two essential processes: it supports the particularization of meanings by constraining the cognitive process of meaning construction, and by eliminating ambiguities or concurrent meanings that do not seem to be adequate at a given moment; on the other hand, context also prevents this particularized meaning from being isolated as it brings about coherence with a larger whole.

Context plays then an essential role in students' meaning construction. Our assumption is that, similarly, insight cannot be gained ${ }^{1}$ from research outcomes without a deep implication of a

\footnotetext{
${ }^{1}$ The metaphor "to gain insight into something from research findings" is very popular in research, emphasizing the fact that research results or outcomes are not useful in themselves if they do not "shed light" on some overarching question, issue or phenomenon. Like "meaning" in cognition, "insight" needs a context for disambiguation and for coherence with a larger whole.
} 
context in which these outcomes are produced or interpreted. In the next subsection we take the example of a production of a particular research outcome in a given context, and how it has been interpreted more or less successfully in other contexts. It helps to introduce the idea of re-contextualization, to specify hypothesis and questions and to prepare a presentation of the notions used through the paper to address contextual issues.

\section{An example of relationship between research outcomes and context}

In this sub-section, we take an example of contextual issues attached to research outcomes. We consider theoretical frameworks as a particular outcome of a stream of research studies, and research at international level as a field for communicating about this outcome. We discuss how contextual characteristics in this stream of research studies mediated communication.

During the decade of the 1990s, there was a big interest in Computer Algebra Systems (CAS) and complex calculators embedding CAS, as a support for learning mathematics. Monaghan (2005) explains how research studies were carried out differently in various regions of the world. Researchers in France experimented with CAS in the classroom, first to evaluate its effectiveness, but also to address overarching questions relatively to the integration of technology. The instrumental approach (Guin \& Trouche, 1999, Lagrange, 1999, Artigue, 2002) was one outcome of this stream of research. French CAS researchers turned to research on instrumented activity (Vérillon and Rabardel, 1995) that distinguishes between an artefact, as a material object, and an instrument as a psychological construct: "the instrument does not exist in itself; it becomes an instrument when the subject has been able to appropriate it for himself and has integrated it with his activity" (p. 84).

Researchers in France also drew from Chevallard's (1999) anthropological theory of didactics to build an 'anthropological approach' to technology use. The notion of praxeology (tasks, techniques, theories) was especially helpful: praxeologies are tools in teachers' hands to organize students' learning; technology introduces new techniques, concurrent to existing ones, and then most often requires to reconsider existing praxeologies and to create new praxeologies. Techniques in the sense of the anthropological approach are then crucial in the integration of technology (Lagrange, 2000, Artigue, 2002).

The first contextual characteristics that we discuss here are CAS, the artefact involved, and the school level where it is used: CAS is a complex artefact which incorporates various computational media (Cuoco, 2002) and is offered for advanced mathematics at upper secondary and tertiary level. The other contextual characteristic is the French tradition in didactics as outlined by Sriraman and English (2011, p. 24), not independent of the French cultural context.

French CAS researchers communicated at international level about the instrumental and anthropological approaches. This kind of communication can be seen as a "decontextualizition" of research outcomes and it was successful in making these outcomes known in international mathematics education. However, in our view, this process also brought misunderstandings resulting from insufficient reflection on contextual characteristic outlined above. First, many researchers working on the educational use of other software or at other school levels maintained that "there is no instrumental issue" with the "simple" artefact(s) they used, implicitly assuming that the instrumental approach is deeply dependent on the complexity of the artifact and of the school level, a characteristic of the CAS context. Second, differences in cultural contexts had a strong influence on how the anthropological approach was received in the international community. The anthropological approach derives from a sociological framework initiated by the French anthropologist Marcel Mauss giving 
much emphasis to knowledge as a product of a human activity deeply rooted in society, seen via the lens of institutions (Lagrange, 2013). In the context of France, the notion of technique, understood as a way of solving tasks in a given institution, is present in the culture. In other contexts, long established views especially about algebra strongly separate skills, considered as meaningless, from understanding. These views do not distinguish techniques from skills and therefore can hardly integrate a contribution of techniques to understanding ${ }^{2}$.

These contextual misunderstandings persisted along the years 2000, but it is now accepted that even simple artefacts like compass and ruler in geometry need an instrumental genesis (Bartolini Bussi \& Mariotti, 2007). Researchers like Kieran and Drijvers (2007) refer to the Task-Technique-Theory (T-T-T) framework, as adapted from the anthropological approach, to study the emergence of epistemic actions within technique-oriented algebraic activity. Then, overcoming these misunderstandings in the diffusion of French research outcomes took time, and in our analysis, was the result of a work of re-contextualization by researchers working in other contexts. Researchers working in the area of Dynamic Geometry first recognized the relevance of an instrumental approach (Laborde, 2001) before extending to other non technological artefacts used in geometry or more generally artefacts to work in mathematics (Bartolini Bussi \& Mariotti, 2007), a field in which they did significant work before. Kieran (2004) did not especially consider technology, but was rather interested by an approach that should help to think of the epistemic role of techniques for a meaningful algebra, a domain of research that she explored extensively before.

\section{Hypothesis and questions}

This example is particular in the sense that it considers 'approaches' as outcomes of research, and the international mathematics education community as a field for communication. However in our view an extension to other outcomes and fields is workable. Mathematics education research is not different from other activity in the sense that the context in which somebody works on a particular domain mediates his or her understanding of important aspects of this domain. Our assumption is then that we can extend the reflection to other research outcomes. For instance, the low impact of research on the reality of school use of technology to teach and learn mathematics can be seen as the consequence of misunderstandings similar to those raised above.

Our hypothesis is that specifying and explaining general characteristics of a research context is necessary for the communication but it is not sufficient in itself: research outcomes can only be meaningful after re-contextualization and then research should bring not only outcomes and contextual data, but also effective means for re-contextualizing to other contexts. This calls first for a better understanding of how a researchers' context is constituted, and for promotion of methods to progress towards more systematic ways of recontextualizing research outcomes, using our experience in the cross-studies.

The questions raised are: how can we conceptualize researchers' contexts in view of their mediating role? Which contextual characteristics are important, in view of which research outcomes? How do cross-studies help to investigate these contexts? What is important in this method for a successful re-contextualization?

\footnotetext{
${ }^{2}$ Monaghan (2009 p.23): “the term 'technique' in my country's everyday mathematics-education-speech refers to value-free manipulation".
} 


\section{Objects involved in contextual issues}

We now specify more the objects involved in the above questions: outcomes and contextual characteristics of a research study. In order to identify the kind of research outcomes that might be affected by contextual characteristics we start from problems arising from insufficient consideration of the context in research studies.

One problem is the difficulty of interpreting the behavior of teachers and learners participating in the empirical part of the study, given that this behavior is situated within a complex web of contextual circumstances. This difficulty clearly impacts on the reliability of research results since it is a basis for drawing conclusions relatively to research questions. The interpretation of this behavior often takes the context into account to acknowledge the limits of the study, but in our view research has to go beyond acknowledgement and identify

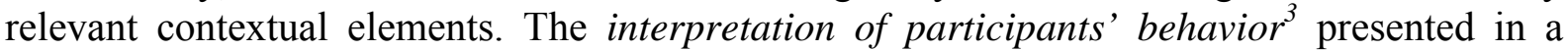
research study as evidence to draw conclusions will be the first kind of outcome considered here.

Another problem is the fuzziness of the messages coming from research in mathematics education to the outside world including educational policy makers, teachers and learners in the society at large. We are interested here especially in the case of researchers communicating with this outside world by producing resources that might be useful outside research, and here, given our focus on digital media, we consider especially resources like digital media -that is to say software dedicated for classroom use- and the associated classroom scenarios of uses-that is to say propositions of classroom implementation of the digital media for given objectives. We assume that the limited impact of theses resources and more generally of the messages addressed by researchers to the outside world is a consequence of the unawareness of how the context of their studies affects their findings. Created in a given context, these resources are generally problematic in other contexts. Here also identifying contextual elements that may affect diffusion is not obvious: the resistance to or acceptation of innovation proposed by research may have many different roots. Resources like digital media and scenarios will be the second kind of outcomes considered here.

A third problem is that theoretical frameworks-or approaches- used and developed in research studies inevitably emerge from specific social and cultural contexts. As shown in the above example, social values and epistemologies of mathematics and mathematical activity in this context play a big role, not easy to elucidate. Because these values and epistemologies are mostly implicit, theoretical frames used and emerging from these studies are hard to read by outsiders and their clarity and applicability in wider scales than those addressed by the researchers is problematic. Recently, relatively to theoretical frameworks, interest grew upon the role of communities and cultures. Monaghan (2009 p.18) implicitly acknowledges the role of the cultural context in the appreciation of a theory when he refers to comments from a South African mathematics educator on attempts to import learner-centered instruction from the USA into South Africa classrooms. Theoretical frameworks are then finally our third kind of outcomes. It is the most visible outcome emerging from research, especially at an academic international level. The multiplicity of frameworks in mathematics education is a motivation for a large stream of research to which Artigue \& Mariotti (this volume) contribute. Here we specifically explore the nature of frameworks, both product within a context and participating in this context, as outlined in the above example.

\footnotetext{
${ }^{3}$ Italics are used in the rest of the paper to indicate that the notions are to be understood as they are introduced in this section.
} 
As for context, Van Oers (ibid p. 481) warns that it is not at all static and impersonal:

A context is constructed by an agent every time he gets actively involved in a setting: by determining his particular goal, examining his prior experiences, finding out which means are available, investigating which actions make sense to perform in order to achieve the goal chosen, and by relating motive, goal, object, means etc. Context, then, is the result of this process of identification of a situation as a particular activity setting.

We distinguish between two kinds of activity settings within which researchers construct their context: the empirical settings where experimental research takes place and the academic settings where researchers prepare and exploit empirical research, communicating with other researchers and the wider world. Context in empirical settings is characterized by teachers, students and other actors chosen to take part in empirical research, their relationship with the artifact(s) at stake, and between them, as well as policies and pedagogic norms at several levels from school, to curriculum and assessment regimes, and to national education systems and, etc. Context in academic settings includes the institutional and cultural environment within which researchers choose to work, particularly the relationships to and expectations of funding agencies, their positioning in relation to colleagues locally, nationally and internationally as well as their relationships with teachers and school for empirical research.

Research outcomes and contextual characteristics are linked in multiple ways. While contextual characteristics attached to teachers, students and other actors chosen by researchers to participate in a research study are influencing research outcomes, these outcomes also have an impact on these characteristics, since new research questions will emerge, whose investigation will require building an adequate context. Also theoretical frameworks emerge under the influence of contextual characteristics, and they are important elements in the academic settings. There is then an entangled "circular" relationship between outcomes and characteristics whose elucidation requires special choices and methods outlined in the introduction, and that we develop below.

\section{Choices and method}

\section{Focus on design and intervention}

Starting this paper, we expressed our concern that, at least partly because of contextual misunderstanding, research in the uses of digital media for the learning of mathematics had little impact on actual classroom practices. This field is then, among others, a good choice for studying context. Inside this field, we choose to focus on two dimensions that we think particularly relevant with regard to context.

Our first choice is to focus on the design dimension. Researchers designing digital media and scenarios, base their work on their more or less implicit perceptions of learning mathematics and their epistemologies of mathematics and mathematical activity as well as on the rules and constraints of software production and dissemination. At the same time, users shape their conceptualizations of the nature of these media in a process of instrumental genesis (Vérillon \& Rabardel, 1995) influenced by perceptions and epistemology together with rules and constraints of schools and classrooms. Then we expect that design issues will bring forth the role played by characteristics influencing design in the academic settings and the way characteristics in the empirical settings influence perceptions of the media by users.

The second choice is to base our relationship to the empirical settings on an interventionist agenda. Researchers with an interventionist agenda aim to study how new visions of mathematics teaching/learning underpinning some particular technology use can be infused 
into existing practices and then they seek to intervene in ordinary school settings. This implies building a context in empirical settings facilitating intervention, but also representative of resistances to new visions assumed to exist in common school settings. We expect that observing this construction of a context with dual character-facilitating and resisting-will provide insight into the complexity of the relationship between research and context.

\section{Method}

We indicated in the introduction that the central method in ReMath was cross-study. As explained in the introductory paper of this issue (Kynigos \& Lagrange, this volume), six sets of two studies were carried out by two teams collaborating with each other when it was needed. For each pair of studies one DDA was used. One team was in charge of the design and development of the DDA and the other was not. The method implied then three steps (a) the design of the DDA by the team in charge (b) a cross-experimentation of each DDA, based on teaching experiments carried out by two teams, one being in charge of the design, each in its own context and (c) two cross-case analyses carried out in common based on these teaching experiments.

Relatively to step (a) we were aware that design decisions have a strong impact on the three kinds of research outcomes identified above in research studies about digital media. The participants behavior depends on characteristics of the DDA in use and on the situations of use, often at the detail level (see Jackiw, 2010, for a discussion on how details count in digital media design). Design decisions are at the basis of media and scenarios offered to the outside world. They have also an impact on theoretical frameworks built on the use of digital media; consider for instance basic choices done in the implementation of Logo, in the context of Artificial Intelligence research and how they cannot be separated from the constructionist framework. These influences and the ensuing decisions are generally mostly implicit. In contrast designers often insist on how the design at a general level is supported by theoretical approaches but generally metaphorically more often than operationally. In addition, design decisions are under influence of contextual characteristics, both in the empirical and in the academic settings; the design must produce a DDA both innovative and acceptable by users in the empirical settings and it has to give way to a viable development taking into account academic constraints.

Relatively to step (b), we understand teaching experiments (Steffe \& Thompson, 2000) as means to validate, refine and re-formulate hypotheses, and not as "control/experimental group" research methods. The teaching experiments were designed as means to address research questions related to the potentialities of the DDA for "representing mathematics". We do not especially discuss these questions here, because this is the central topic of other papers in this volume (Morgan \& Kynigos, this volume, Artigue \& Mariotti, this volume). We concentrate on the research outcomes identified above: the DDAs and the scenarios designed and experimented by both teams, the interpretation of participants' behavior presented as evidence for drawing conclusions, and the role of theoretical frameworks.

One intention in step (c) was to investigate which elements of the context raised the greatest problems for the teams in the design and the implementation of the teaching intervention. We thought that an explicit reflection on how context affected the implementation and the exploitation of each Teaching Experiment was especially important in this step.

In the next two sections, we consider successively an analysis of the DDAs' design relatively to context, particularizing to the two DDAs, named Casyopée and Cruislet, and then we 
exploit the cross-studies carried out around each of these DDAs. The DDAs' design and the cross-studies involve three teams: DIDIREM ${ }^{4}$ in France, the team in charge of the design of Casyopée, UNISI in Italy and ETL in Greece, the team in charge of the design of Cruislet. This choice is motivated by several reasons. As we see in the next section, these DDAs situate differently in terms of relationship with the empirical context. Their designers rely on different theoretical approaches. Three European countries are represented with the diversity of their educational systems and constraints. Moreover these teams cover the diversity of theoretical approaches at stake in ReMath, (Artigue \& Mariotti this volume). We do not present more details about the teams at this stage. The contextual characteristics, important for our study, are made explicit when they appear in the analysis. Finally, we focus more particularly on the DIDIREM team that participated in both cross-studies, in order to exploit phenomena that the cross-studies highlighted and to question in depth one team's context.

\section{Design issues}

\section{DDAs’ design in context}

In ReMath, one goal was to make explicit researchers' positions with regard to particular concerns. The hypotheses was that, beyond theoretical perspectives used, researchers could have a better view of what they have in common and what distinguishes them by clarifying the way they deal with specific concerns related to the use of digital technologies. To organise the concerns influencing the design of each DDA, the ReMath teams used the notion of didactic functionality of a digital artefact that Cerulli \& al. (2006) defined by giving three key elements (1) a set of features and characteristics of the artefact, (2) educational aims and (3) modalities of employing the artefact in a teaching/learning process referred to the educational aims. It allowed the teams of designers and experimenters to have a more operational view of the potentialities of each DDA and concretized into "epistemological profiles" with which each of the DDA could be analysed and appreciated (Artigue, 2009).

\section{Two DDAs and their epistemological profiles}

We present the two DDAs and their relationship with the context in which they emerged.

Cruislet is a navigation microworld in which users direct 'avatars' (air transportation vehicles) across the Greek geography by issuing navigation instructions in either graphical/Cartesian or spherical/polar coordinate systems, in direct stepwise mode or by way of Logo programming. Avatars' movements are defined in terms of displacement vectors, and must take into account not only the location, but also the elevation of the landscape they are navigating. Cruislet has been developed by a private company on the basis of an existing geographical system, under ETL's specifications.

Casyopée is oriented towards problem-solving, modeling and proof with mathematical functions, and offers special assistance for this activity. It includes two connected windows: a symbolic and a dynamic geometry window. Casyopée's design had been initiated some years before ReMath, and nurtured by the development of didactic research on functions and algebra. As shown by Lagrange and Artigue (2009), innovations were introduced during the ReMath project in terms of dynamic geometry, geometric calculations, support for modeling activities, but obeyed the same logic, relying on categories and constructs offered for instance

\footnotetext{
${ }^{4}$ DIDIREM is now integrated into the Laboratoire de Didactique André Revuz, University Paris-Diderot, UNISI was a team in Università degli Studi di Siena, ETL was a team in the Educational Technology Lab, NKUA Athens.
} 
by Tall (1996) and Kieran (2007). Beyond this influence of theories of algebra learning, the decision to develop Casyopée was also a consequence of the research on the use of Computer Algebra Systems (CAS) mentioned in the first section. More precisely Casyopée emerged from the idea that the instrumental complexity of standard CAS like for instance Maple or Derive was an obstacle to their integration in secondary schools.

After this general presentation, we organize the study of the design of Cruislet and Casyopée using the above mentioned 'epistemological profiles' and following the three entries defining the didactic functionality of a digital artifact.

(1) A set of features and characteristics of the artifact.

Cruislet's epistemological profile puts at the first place a 3D geographical map of Greece that can be navigated via tools now popular in software like Google earth. The context of Greece has been chosen with the idea in mind that students will adopt more willingly the DDA, recognising and exploring a familiar environment. As a system of geo navigation, Cruislet is also intended to be recognised by students as a contemporary tool. Relatively to the mathematical concepts that students can approach through situations with Cruislet, the Cruislet team mentions that "All geometrical and algebraic concepts deriving from (the) mathematical kernel are available for mathematization from the students such as geometrical shapes and curves, vector operations and functions" without making reference to a curriculum.

The Casyopée epistemological profile brings forth a central concept "mathematical function of one variable". This concept is seen through complementary aspects, geometrical dependencies and real function of a real variable with standard mathematical representations. The Casyopée team stresses that this view of functions is encouraged by the curriculum, but impossible to address properly by most students with paper-pencil or existing (dynamic geometry or CAS) software. In Casyopée, the two aspects are implemented as a set of features present respectively in the geometrical and in the algebraic windows, and another windowgeometrical calculation- helps to connect the two aspects.

Clearly, the curriculum is the main contextual characteristic influencing basic choices in Casyopée, while the Cruislet team considers students' engagement as a priority. Both characteristics belong to the empirical settings.

(2) Educational aims.

The Cruislet team describes the educational aims that can be attached to the DDA in a rather general and open way: to provide a medium with which to question the curriculum structure and to stress the need for applied meaningful mathematics as a medium for mathematical meaning making. They say that a lot depends on the activities designed with the use of Cruislet and the context in which it is inserted. They mention the possibility of making distinct connections with the standard curriculum and organizing special activities for students to make these connections with school mathematics. They stress also that Cruislet can be a basis for "more exploratory meaning making activities" where students "gradually mathematize" the ways in which they construct avatar trips.

Casyopée's educational aims are explicitly based on a typology of student activities in the domain of functions (Lagrange, Artigue, 2009). This typology organizes the activities at three levels -dependencies between objects in a physical setting, dependencies between measures and algebraic functions, and relatively to different representations of concepts in calculus : enactive-iconic and algebraic. Different types of activities are proposed and the way students can perform and connect these with the help of the DDA are discussed. The educational aims 
are related to students' understanding of functions through these activities, making students encounter different aspects of functions, and build connections between these.

Clearly, the educational aims are deeply influenced by the team's theoretical orientations: constuctionism for the Cruislet team, and a priority for an epistemological approach of functions for the Casyopée team. Both characteristics belong to the academic settings.

(3) Modalities of employing the artefact in a teaching/learning process.

The modalities of employing exposed by the Cruislet team are consistent with their theoretical perspective, constructionism. The team says:

through the use of the Logo programming language the software becomes constructionist in the sense that avatar trips can become parametric models of sequences of displacements. Procedures constituting half-baked microworlds can be designed in the sense that students can observe the trips they define and then change the procedures to make changes to the trips.

The Cruislet team recognizes that in designing the DDA and the tasks it took some distance from the traditional structure of the mathematics curriculum as to involve students in activities through which they would use symbols, make and verify hypotheses in a rich learning environment and additionally, to have a better understanding of the curriculum traditionally taught. These modalities of employments are then thought in relationship with the empirical context: the goal is to show how, in real class settings, students may have richer mathematization processes.

The Casyopée team insists on the easy use of the DDA and the consistency with standard notation and objects, contrasting with existing CAS. This is thought in relationship with the empirical settings: teachers, and more generally the school institution are reluctant towards CAS use for many reasons, and then one goal of the team is to propose modalities of employing Casyopée making CAS acceptable in these settings. Activities, especially modelling of geometrical dependencies, that Casyopée favours, are compatible with the curriculum or can prepare an evolution of the curriculum. The team thinks that they are not feasible by students with existing software, and this is a motivation for developing Casyopée.

This analysis of modalities of employing the artefact shows a different approach of the empirical settings. The Cruislet team wants to promote new possibilities for students' mathematization processes complementary to the curriculum, while the Casyopée team wants to offer a new tool for a better implementation and an evolution of the curriculum.

Summarizing the three entries defining the didactic functionality of a digital artefact, we see that the theoretical orientation of each team, a characteristic of the academic settings, influences each DDA's design principally at the level of the educational aims. Each team has its own vision of the empirical settings conceived at a global level. These visions influence the design of the features and characteristics of the artefact and of the modalities of employing. For the Cruislet team, the vision is oriented towards the students, how they will adopt the DDA and how it will engage them in mathematisation independently of the curriculum. In contrast, the Casyopée team sees the curriculum and its possible evolution as a source of inspiration. The acceptability of the DDA is expected from the compatibility with the curriculum and from the help that the DDA is able to bring for a suitable implementation. The vision underpinning Casyopée's design is not limited to the actual curriculum but, making the DDA acceptable is seen as means to introduce a reflection preparing evolutions. Certainly the different history of the teams explains the divergent construction of the context by the two teams. Farther below, we go deeper into this history, when analysing particularly the Didirem team in charge of Casyopée. 
Both teams do not specify the level at which the empirical setting is taken into account. From the analysis below, one can infer that it is the national level (Greece for Cruislet and France for Casyopée) or a particular local context in these nations, but, certainly, the teams assume implicitly that the DDA will be usable in other settings. Cross-studies mentioned above were conceived as means to question this assumption and to investigate how teams from other settings could take advantage of the DDA. In addition, this method was intended to shed light on other contextualized design decisions not mentioned in the DDA's profile written by the team and probably unconscious.

\section{Cross-studies}

We exploit successively Casyopée then Cruislet cross-studies. This exploitation does not enter into details, but rather outline the main features, in order to introduce unexpected phenomena or disappointments brought into light by the cross analysis. The analysis of these phenomena, under a "contextual lens" follows in order to tackle the question of re-contextualization. As announced above, the choice has been made to consider phenomena questioning one team's approach of the use of the two DDAs, and then this team is DIDIREM, and the question of recontextualization is particularly considered from this team's point of view. In this presentation, we refer to theoretical frameworks as contextual characteristics of the teams, but not enter into details since these frameworks are the object of another article in this volume (Artigue, Mariotti, this volume).

\section{The Casyopée cross-study}

\section{Contextual characteristics in the cross- experiment}

In this subsection, we exploit the cross-experiment of Casyopée, comparing the teaching experiments' scenarios and their implementation in relationship to contextual characteristics. The French team DIDIREM included the designers of Casyopée. This is a first characteristic in the academic settings that also points towards previous work and theoretical orientation mentioned in the above discussion of Casyopée design. In addition to the epistemology of functions inspiring the design, the DIDIREM team relied on the anthropological theory of didactics (ATD), and the instrumental approach (IA) both briefly presented in the example of the introduction, and of the theory of didactic situations (TDS) (Brousseau, 1997). The ecological perspective of ATD made them especially sensitive to institutional constraints and norms, and this sensitivity, also shared by the two teachers involved in the experiment, deeply impacted the scenario they built together. The scenario was built in order that each session could be seen by students as a clear step in the curriculum progression, an implicit institutional request in France.

This scenario also paid great attention to the progression of instrumental genesis and to the way mathematical knowledge and knowledge about the artifact intertwine, clearly under the influence of IA in its ergonomic dimension.

TDS defines the student as a subject who acts on an antagonist milieu. The milieu reacts to his/her actions through feedbacks which she/he interprets in the light of her/his knowledge. Learning occurs in the interplay between actions and feedbacks and then the design of a teaching intervention requires creating situations which allow students to construct the knowledge at stake as an optimal answer to the tasks involved in the situation, without the help of the teacher. Such situations are called a-didactical situations.

Consistent with TDS, DIDIREM's scenario and its implementation paid attention to the careful choice of tasks and control of the didactical variables of these in order to optimize the 
cognitive effects of the students' a-didactical interaction with the milieu provided by Casyopée. Note that, according to TDS, a-didactical phases are not a goal in themselves, but are included inside a didactical process where knowing built through a-didactical interaction is progressively "formulated" to allow a "validation" and linked to standard official knowledge through "institutionalization". However, the scenario did not explicitly refer to this process, mainly focusing on the problems offered for students' a-didactical interaction, on their epistemological relevance and on the help offered by Casyopée's didactical functionalities in this interaction. This focus on a-didactical phases can be also put into relation with a common stance in French school mathematics, that student have to be actively involved in problem solving as a preparation for accessing concepts.

The scenario then clearly reflects both the team's theoretical orientations and characteristics of the French school mathematics setting.

The scenario by UNISI was convergent with the scenario by DIDIREM in the sense that it exploited the same features and characteristics of Casyopée, putting at stake the same problem of geometrical optimization (Maracci,Cazes, Vandebrouck \& Mariotti, 2013). This reflects a common epistemological approach to functions in the two teams, and also a tolerance of the Italian school mathematics towards "foreign" tools (for instance, Casyopée had not been translated into Italian). The scenarios however strongly differed at the level of the educational aims and of the modalities of employment. In France, the experiment at $11^{\text {th }}$ grade aimed at contributing to a specific part of the curriculum, while in Italy the experiment was carried out at $12^{\text {th }}$ grade and aimed at a synthesis of knowledge about functions previously learnt, thanks to the new approach allowed by Casyopée. The experiment was also longer comparatively to that carried out by the French team. It seems that there is less institutional pressure in Italy and that a long teaching experiment privileging reflection is more easily implemented as compared to France.

This reflective dimension of the UNISI scenario was concretized both at the local level of the teacher classroom activity and at the global level of the organization in "didactical circles" including specific sessions for classroom discussion. This reflective dimension is also consistent with UNISI's theoretical framework of reference: the theory of semiotic mediation (TSM) (Bartolini Bussi \& Mariotti, 2008). TSM considers that in a mathematics class, when using an artefact for accomplishing a mathematical task, students can be led to produce personal signs which can be put in relationship with mathematical signs. The construction of such relationship should be assumed as an explicit educational aim by the teacher, who can intentionally orient her/his own action towards promoting the evolution of signs expressing the relationship between the artefact and the tasks into signs expressing the relationship between the artefact and the knowledge at stake. This theoretical choice also influenced other choices in the scenario design. For instance, while the UNISI team and the DIDIREM team share a common reference to Rabardel's constructs, the way instrumental genesis was approached in the two scenarios differed: while, the French scenario organized a progression in the instrumental genesis, the Italian choice was to present all relevant features of Casyopée in a first session and then implement six sessions structured "in iterative didactical cycles entailing: (a) students' pair or small group activity with Casyopée, (b)students' personal rethinking of the class activity and (c) classroom discussion orchestrated by the teacher" (Maracci et al, 2013, p. 465).

Again here, the UNISI scenario appears as a convergence of the team's theoretical orientation and of possibilities offered by the Italian school mathematics settings.

With regard to local settings, the main feature is that the two teachers in the DIDIREM experiment were members of the research team designing and experimenting Casyopée and 
were closely associated to the scenario design. In contrast, the teacher involved in the implementation of the UNISI scenario was not member of this research team and had no previous experience in managing classroom discussions as framed within the Theory of Semiotic Mediation. We come back below to this difference in order to go deeper into how this characteristic of teachers mediated the experiment and the results.

\section{Cross-analysing Casyopée's experiments: re-interpreting participants' behavior in empirical research}

Each team, DIDIREM and UNISI did first an analysis of its own experiment in a process of selecting data, decomposing transcripts into episodes, interpreting these and inferring conclusions. Each cross-analysis started from this first analysis and both teams looked critically to every step of this process. While exploiting both cross-analyses, consistent with our choice to focus on one team, we particularize here to DIDIREM's Casyopée experiment,

DIDIREM's a posteriori analysis of its own experiment was positive. The scenario had been negotiated with the teachers and had been implemented in the expected period of time. Students and teachers actually appreciated that the scenario was well and timely situated into the planned curricular progression. The researchers were happy that Casyopée's design allowed students' a-didactical interaction with a "milieu" and that teachers had been able to take advantage of this interaction.

However, the cross-analysis brought disappointment, questioning DIDIREM's results with regard to the way the experiment could provide evidence of students' mathematical attainments (Artigue, 2009 p. 50). Because of their focus on the process of semiotic mediation and on the management of this process by the teacher, UNISI especially questioned DIDIREM's data and analysis as evidence of full students' mathematical understanding of actions with Casyopée. While in TDS, the process of formulation and institutionalization allows mathematical knowledge to emerge from students' a-didactical experience, DIDIREM had to recognize that no real data existed to give account of this process. As said above, the scenario and the analysis did not explicitly consider phases of formulation and institutionalization, privileging a-didactical phases and trusting teachers for the other phases. In the a posteriori analysis, small episodes of institutionalization were found mainly in the interaction between teams of students and teachers. The problem is that in the episodes observed, students were very quickly imposed linguistic forms distant from the language of action describing the activity of solving with Casyopée, an evidence of a weakly managed process $^{5}$. As a difference, the analysis of UNISI's experiment showed rich semiotic processes resulting from the careful management of classroom discussions by the teacher and then revealed a "semiotic potential" of the DDA, of which the designers were not aware.

The cross-analysis then revealed an underestimation of the complexity of the semiotic processes at stake, in the transition from activity with Casyopée towards awareness of the mathematical knowledge implicitly engaged. A consequence of this underestimation is that the DIDIREM team, in spite of its focus on TDS, did not take enough care of the formulation and institutionalisation processes leaving these to the decision and improvisation of the teachers. Further evaluation of students' attainments, carried out in doctoral work (Minh,

\footnotetext{
${ }^{5}$ For instance, a shift of a graph occurring while animating a parameter in the formula of a function was quickly interpreted by the teacher as the effect of a geometrical transformation, and in Maracci et al (2013, p. 474)'s analysis "there is the risk that the meaning attached to (this mathematical concept will be) confined to the actual use of Casyopée".
} 
2012) confirmed that, after the experiment, the students could not really make sense of crucial steps in the solution of the tasks.

This discrepancy between the positive appreciation by the DIDIREM team after the experiment and the disappointment following cross-analysis can be put into relation with contextual elements:

\section{- Contextual characteristics in the empirical settings}

The strong institutional and cultural pressure in France especially at upper secondary level requires that every session has to be understood by the students and the school environment as a visible step in the curriculum progression. Making the student "active" is also very encouraged by the curriculum and the authorities, even if the way this activity can be productive is something of a black spot. As mentioned above, part of the satisfaction following the experiment came from the fact that the scenario was well and timely situated into the progression of knowledge and also from students' active involvement in the tasks. It is then obvious that satisfying curricular, institutional and cultural norms implicitly played a role in the positive appreciation given by the DIDIREM team, even if these norms overlook crucial semiotic dimensions of learning as well as the subtle processes of institutionalization.

\section{- Contextual characteristics in the academic settings}

The teachers and the schools had been involved in the Casyopee project since the beginning. The Remath experiment was one in a succession of experiments over ten years accompanying the evolution of the project. However, previous experiments privileged observation of the students' interaction with the software and evaluation of its potential, trusting the teachers for establishing conditions for the mathematical productivity of this interaction. Actually a team of teachers involved in a project like Casyopée and working in a favorable school environment is very precious for researchers. The relationship between researchers and these teachers is complex with regard to didactical expertise. The teachers cannot be thought of as "actors" playing a part prepared by the researchers. They can have a deep didactical reflection but establishing a scenario really consistent with a TDS approach would have required setting up a dialogue on the specific phases of a teaching/learning situation and their management by the teachers, considering the different expertises, of practitioners driven by their experience on the one hand and of researchers driven by their theoretical background on the other hand. "Applying" TDS would have been considered artificial. In the dynamic of a project like Casyopée, no occasion had been found before to deeply discuss explicitly the issue of conceptualization following students' activity with Casyopée. As a difference, the teacher in the UNISI experiment was not a member of this research team and researchers had to explain her role in managing classroom discussions as framed within the Theory of Semiotic Mediation. More data were available from UNISI experiment about semiotic processes, giving evidence of an actualization of Casyopée' potential, as compared to DIDIREM's experiment.

\section{The Cruislet cross-study}

The second case we consider is the Cruislet cross-study.

\section{Contextual characteristics in the Cruislet Teaching Experiments}

DIDIREM and ETL were the two teams experimenting with Cruislet. As has been already noted, Cruislet's design is not directly aimed at a specific mathematics curriculum and the knowledge at stake with Cruislet is interdisciplinary, at the interface between geography, mathematics and programming. Both teams' teaching experiment scenarios were 
consequently disconnected from the curriculum but with dissimilar consequences. In Greece, a rather long experimentation was organized in grade 10 classes $(20 \mathrm{~h}$ in one class, $8 \mathrm{~h}$ in the other one) without difficulty. In France, making the use of Cruislet compatible with institutional constraints obliged the experiment to take place in very specific circumstances, first multidisciplinary project work, at grade 11, and then university workshops for grade 9 students. Moreover, in France, the negotiation of the scenario with the teachers in charge of the first experimentation was a rather difficult process: the teachers complained that they were not familiar enough with the DDA and that it would be difficult to engage students into activities that they would not recognize as contributing to mathematical learning consistent with the curriculum. The influence of the empirical settings in the scenario design is then immediately visible: as noted above, in France every session has to be understood by participants as a visible step in the curriculum progression and this does not make it easy to implement a scenario with a DDA like Cruislet.

From a theoretical point of view, references to constructionism helped the ETL team to exploit directly Cruislet's features and characteristics. This leads ETL to use Cruislet as a tool to develop half-baked microworlds, and to take advantage of the potential offered by the complex linkage of representations offered by this DDA for investigating the mathematical meanings that students construct regarding the notion of function as co-variation of displacements while navigating in 3D large-scale space. For that purpose, students were asked to explore and decode black-box Logo programs defining the relative displacements of two avatars, and then were encouraged to build their own rules, produce associated Logo procedures and thus create new similar functional games.

The situation is radically different for DIDIREM. As indicated above, from a theoretical point of view, the global references are the Instrumental Approach (IA), ATD and TDS. IA and ATD strongly influence the perception of Cruislet's didactical functionalities and thus the design of the experiments. IA leads to paying particular attention to the instrumental genesis of such a DDA, so complex and so far from algebraic or dynamic geometry environments, and obliges to find ways for such a genesis in the short time compatible with the French curriculum. ATD makes the DIDIREM team especially sensitive to the difficult ecology of Cruislet in the French educational system. For DIDIREM researchers, epistemology is a top concern but they could not rely for supporting their design on a stabilized didactic knowledge because the literature regarding the objects implemented in Cruislet, vectors, systems of coordinates in 3D space and algorithmic structures, is not enough developed. Moreover, Cruislet's feedbacks were not designed with an a-didactical interaction in view: for instance, DIDIREM wanted to offer students a task of flying a plane from one town to another, as low as possible; when trying a programmed flight, it happened most often then that the plane hit the ground; this could be an adequate feedback, but it was then impossible to stop the procedure in order to try new parameters for the flight, making the interaction very difficult. In such conditions, the kind of controlled design consistent with TDS DIDIREM is used to carrying out, trying to create optimal conditions for the interaction between students and some a-didactic milieu and making the mathematical knowledge aimed at emerging from this interaction as an optimal solution to the problem posed, becomes quite impossible.

Another point in this cross-case study concerns Logo programming. There is no doubt that Logo programming plays a central role in ETL design, in full coherence with the notion of half-baked microworld and the constructionist theoretical perspective (Healy and Kynigos, 2010). The tasks proposed by ETL deeply rely on Logo programming, and seem to obey a general game pattern familiar to the team. Conversely, Logo programming is not embedded in the DIDIREM culture. While Logo procedures were present as "half-baked microworlds" from the beginning of ETL's scenario, DIDIREM introduced programming only in the second 
part of the scenario, after students appropriated the main features of Cruislet. The tasks designed by this team were inspired by examples provided by ETL colleagues during ReMath meetings but DIDIREM adapted these to their particular sensitivities and concerns in two different ways: in the first experimentation, accent was put on iterative structures, through the programming of flights involving the repetition of the same action and the gradual introduction of iterative variables; in the second the accent was put on the differential vision of curves related to their curvature properties that Logo makes accessible with a limited mathematical background and iterative variables are introduced from the beginning. In the two cases, we can see there a manifestation of the DIDIREM sensitivity to epistemological concerns. This particular sensitivity of the researchers, also influenced by their perception of what is possible in the empirical settings, affects the vision of didactical functionalities of the DDA they are not familiar with, influencing the way they exploit these functionalities in the scenarios.

\section{Cross-analysing Cruislet's experiments: towards an extended understanding of the epistemology of functions}

In the cross-analysis DIDIREM did a close study of the ETL experiment. ETL provided more data about the epistemological bases of the scenario and a precise account of students' behavior. For instance, ETL reported on a situation based upon the use by students of a procedure that made one plane perform a flight to an arbitrary position while another reached a dependent position, each of its coordinates being a linear function of the same coordinate of the first one. Using this procedure first as a black box and then decoding the procedure, students could make sense of the situation by investigating the co-variation of the planes and conceiving the first plane's position as an independent variable and the second plane's position as a dependent variable (Markopoulos et al, 2009). Analyzing DIDIREM' teaching experiment, ETL also pointed out that few of Cruislet's features had been used in the DIDIREM teaching experiment. Finally, the cross-analysis made clear that Cruislet had the potential to allow students to construct the notion of function as co-variation while navigating in a realistic 3D large scale space. As indicated above, functions as model of co-variation were also a domain of interest for DIDIREM. However, the domain of co-variation at stake in Casyopée is 2D geometry and the functions are one variable real functions. In addition, Casyopée is designed to help investigate polynomial, rational or transcendental functions rather than linear functions. Thus, when designing the scenario, DIDIREM researchers, although informed by ETL of the tasks prepared by this latter team, did not notice the interest of these tasks for students' learning about functions. It is worth to note that, in the constructionist tradition, no a priori analysis of students' behaviour was made by ETL for the cross-experiment, which did not help DIDIREM to recognize the potential of these tasks for their scenarios. On the contrary, the cross-analysis of the ETL Cruislet cross-experiment, focused on the students' behaviour and a better understanding of constructionism, pointed out an approach to functions that could be very complementary to the approach with Casyopée.

Designing their experiment, DIDIREM researchers did not consider this approach to functions because of the distance of the tasks proposed by ETL from the usual tasks they were used to with Casyopée. DIDIREM was attracted by features of Cruislet mentioned above offering opportunities to link mathematics and geography in a multidisciplinary approach also favoured by the realistic context of Greece, and to introduce students to programming, the Logo language and the realistic context being a motivation for students. To take advantage of these features, DIDIREM conceived objectives for the teaching experiment. These objectives were necessarily relatively far from the actual curriculum and this is the reason why the experiment could take place during a limited number of sessions and in the frame of a special 
project in the first experiment and of a university workshop in the second. In the a posteriori analysis of the first experiment, it appeared that the scenario had a certain potential to promote new teaching/learning situations but also that students' poor instrumentation of Cruislet in the limited time of the experiment was an obstacle. The second experiment was more successful because it took advantage of this a posteriori analysis to better articulate tasks and also because it was carried out outside the usual classroom context.

This misappreciation by the DIDIREM team of Cruislet's potential for learning about functions can be put into relation with two contextual elements:

- Contextual characteristics in the empirical settings

In the Cruislet experiment, the DIDIREM team was aware of the difficult use of this DDA in the current practices in French classrooms at upper secondary level. The interest of a qualitative approach of functional dependencies, as proposed by the ETL team was not noticed. The perspective of constructionism in which ETL propositions were formulated did also not help to consider these propositions. Research about Logo had been carried out in France during the decade of the 80s, but more in the frame of TDS than in a constructionist approach (for an example, see Gallou-Dumiel, 1987), and this latter perspective has never seemed compatible with the demands of society at large and the school culture especially at upper secondary level. Given this discrepancy both to epistemology and to conceptions of learning, the DIDIREM researchers and teachers identified other opportunities for implementing Cruislet in new trends of the curriculum. The curriculum in France has been debated in the last years (Kahane, 2002). There are significant trends towards seeing mathematics in coordination with other disciplines and towards the development of an algorithmic approach. The DIDIREM team identified these trends as an opportunity to implement an experiment with Cruislet, breaking with current practices, but nevertheless providing a response to specific institutional demands.

\section{- Contextual characteristics in the academic settings}

Casyopée was conceived as an innovative piece of software, but also in close relationship with a group of teachers that were chosen not because they were specially "innovation oriented", but rather because of their ability to create, experiment and disseminate situations that could be acceptable for other teachers. The accompanying epistemology of functions was developed with the idea of real functions of one variable in mind, which seemed to be the easiest notion to implement in the "ecology" of French upper secondary classes. The close relationship to teachers considered as experts, also implied that "changing the pedagogy" was not considered as a priority. Researchers had some knowledge of constructionism, the theoretical perspective on which ETL based its approach, but did not consider sharing this knowledge with teachers as a priority.

The epistemology of functions was questioned when researchers and teachers had to compare the teaching experiments in the cross-analysis. They recognized that the tasks designed and implemented by ETL in a different ecology had the potential to introduce students to a wider understanding of functions that could be useful to consider before or in parallel with the development of competencies in the domain of real functions of one variable favored by Casyopée use. Looking closely at constructionism in the cross-analysis of the ETL experiment was also an opportunity to reconsider this approach, and to discuss it with the teachers, in the light of a similar field experiment. This work carried out in common by researchers and teachers was the basis of a publication intended to share with other teachers what had been learnt (Le Feuvre, Meyrier \& Lagrange, 2010). 


\section{Contextual characteristics and their influence on research outcomes}

Here we draw conclusions from the above reported features of the two cross-case studies, especially considering the context of one team, DIDIREM, which was involved in both crosscase studies. The cross-experiments confirm that the context for a research study is not static and impersonal, but constructed by researchers to allow meaningful research activity. The scenarios for the teaching experiments reflect this construction. We noted that, in this construction, the teams associate contextual characteristics in the academic settings, mainly theoretical frameworks, and features of the national school mathematics settings, especially the degree and nature of the institutional pressure. This implicit construction aims at the consistency expected for an operational intervention. For instance, in the DIDIREM teaching experiments, TDS and ATD appear highly compatible with the French upper secondary level context as if they had been created precisely to coexist with key element of this context, like the strong institutional pressure, the idea that students should be active and that every session must be a visible step in the curriculum progression.

Bringing to the fore disappointments and evidence of missed opportunities, the cross-analyses questioned this consistency as well as more local features of the context, especially the implication of expert teachers, members of the Casyopée research team, in the design of the scenarios and their implementation. This feature cannot be understood without considering the team's history along more than ten years of previous research.

During the decade of 1990s, DIDIREM worked on calls from the ministry of Education aiming at the evaluation of the contribution of computer algebra systems to algebraic learning. It also participated in a meta study of publications in the field of technology and mathematics education also after a call from the ministry (Lagrange et al., 2002). The Casyopée project started from a specific call of the INRP ${ }^{6}$ in the late 90 s, asking for design and development in order to offer CAS based software more adapted to a mathematically productive activity at school level. Fundamentally, answering calls was though of as a way to better understand and discuss the institutional expectations towards research, even when these expectations could not be directly fulfilled.

In DIDIREM's conception, research questions are not hypotheses that can be tested through experimental comparative methods and outcomes are not pure "findings". Overarching questions investigated by DIDIREM deal with the actualization of the potentialities of technology in "real life" teaching and learning, analyzing resistances and pointing out opportunities for change. Empirical research is conceived as a long term intervention into school practices, experimenting digital artefacts and scenarios at the local level of a few schools, disseminating associated resources at a wider level and studying their effects. Outcomes issued from empirical research are a flow of data that helps to get insight into the overarching questions and to reconsider the frameworks in which these questions are expressed, rather than point-like findings. In this sense, research outcomes are the product of a contextually situated activity.

DIDIREM's context has certainly been supportive for this conception of research. As a difference from other countries, official calls did not make a prerequisite of "quasiexperimental" methods and accepted the reframing of questions as a possible outcome. Maintaining relationship with schools on the long term was also possible through the commitment of expert teachers supported by local institutions like the IREM and by national

\footnotetext{
${ }^{6}$ Institut National de la Recherche Pédagogique, named now Institut Français d'Education : http://ife.enslyon.fr/ife/institut/presentation
} 
institutions like the INRP. As a counterpart, this implied for DIDIREM a close connection between on the one hand the questions investigated and the formulation of outcomes and on the other hand the French context both at the global, institutional and cultural level and at the local level of the relationship with the teachers involved in this long term research.

Let us briefly compare this context with the other teams' context especially with regard to the teachers involved.

In the ETL experiment, the teacher was a senior teacher educator trained at the Lab. Because ETL is involved in a longitudinal and wide-scale teacher education project led by the Ministry, the school had an informal trust in this teacher trying out alternative ways to do his lessons with the students; he took one hour from the mathematics lesson and one from the computer science and merged them. So, the intervention in the students' work based on constructionist mathematics was informally respected by the school due to the status of the senior teacher rather than being a result of a systemic channel where the school was obliged or encouraged to do such activities from above.

In the UNISI experiment, the teacher that accepted to collaborate to the project was a newcomer. She participated in the design and the monitoring of the development of the teaching and learning process. She shared with the researchers the main decisions about the general setting of the teaching sequence, in particular the basic structure of a didactic cycle. That means that she had been introduced to the main ideas of the theory of semiotic mediation, and in particular to mathematical discussion as a specific activity of the class, and more generally to the use of the semiotic strategies.

This brief comparison points to a particularity of DIDIREM's context: the special relationship with the teachers involved. These teachers had been participants in research studies with DIDIREM for a number of years on the basis of an implicit and informal agreement relatively to the interest of developing and experimenting with a new CAS environment. Theoretical frameworks and research results were not discussed in depth, this part being considered as the responsibility of the researchers in the academic settings. The teachers were mostly concerned with sharing their interest for Casyopée and the associated situations of use with colleagues and school authorities, and the researchers were happy to collaborate with teachers deeply involved in the empirical settings. In contrast, in the ETL and UNISI experiment, teachers' activity appears aimed towards putting into action the researchers' agenda in the academic settings, rather than towards exploring new possibilities in the empirical settings. Note that DIDIREM's special relationship with teachers had been built through projects following calls from the ministry whose aims were in line with concerns in the empirical settings as well as in the academic settings. So the relationship with teachers at local level reflected the team's relationship to the global French institution.

This special relationship of DIDIREM with teachers had a clear influence on the research activity within the Remath cross-experiments. Previous research carried out in response to French calls prepared DIDIREM for the type of research that Remath put forward. Relationship with teachers and schools provided a useful terrain for discussing and implementing scenarios providing evidence of the possibility of implementing the two DDAs into real educational settings. On the other hand, cross-case analyses carried out with UNISI for Casyopée and ETL for Cruilet pointed out how this context oriented DIDIREM's view on Casyopée and on the epistemology of functions. The cross-case analyses also brought conditions for opening the view: first, the team became aware of the importance and complexity of semiotic aspects in the process of teaching/learning with Casyopée and of the necessity to take full care of the institutionalization process in the TDS framework, and second, the team could enlarge its epistemological view of the notion of function and its 
potential applications, and of approaches of this notion using technology by recognizing Cruislet's potential in this domain.

This is representative of how a team's view of the potential of technology can be dependant on the entanglement of characteristics in its context, restricting the possibility for outsiders to re-contextualize the team's research outcomes. It is also clear that, while this context has been constructed by the team in order to investigate overarching questions, the construction was mainly implicit and the team was not really aware of this dependency. This also highlights cross-analysis as an effective method to explicit and overcome this dependency. In the case of Casyopée and DIDIREM, this effectiveness is attested by practical implications in the dissemination of research outcomes taking into account the need for a re-contextualization: in the above mentioned publication Le Feuvre, Meyrier \& Lagrange (2010) draw from the Cruislet cross analysis to situate the use of Casyopée inside the wide range of possible uses of technology to teach about functions, and in the recent material they publish on line about situations of use of Casyopée ${ }^{7}$, inspired by the cross-analysis carried out with UNISI, they incorporate videos of whole class discussions and in the phases where students work on the computer, they take care to focus not only on the students' behavior, but also on dialogues occurring between students and with the teacher.

\section{Conclusion}

At the beginning of this article, we started from an example where theoretical frameworks were considered as a particular outcome of a stream of research studies, and research at international level as a field for communicating about this outcome. We stressed misunderstandings resulting from unawareness of contextual characteristics and pointed out that a long time and serendipitous circumstances were necessary to allow researchers to overcome these misunderstandings by re-contextualizing in their own domain of research, and then the need for a more effective approach. We tried to identify the variety of contextual characteristics, separating empirical and academic settings, and distinguishing between local and global levels. This is particularly appropriate for analyzing the context of research on the use of technology where activity is done at various levels and articulates both settings.

Returning to the questions formulated at the beginning of the paper, we gave evidence of research contexts being constructed by researchers identifying relevant contextual characteristics of the empirical and the academic settings where their activity takes place, and noted that this construction remains mostly unconscious. We found consistent relationships between contextual characteristics and the DDAs' design: the theoretical orientation of each team, a characteristic of the academic settings, influences design principally at the level of the educational aims. The team's vision of the empirical settings influences the design of the features and characteristics of the artefact and of the modalities of employing. This is important because the features and the modalities of employment are the most visible outcomes in terms of digital resources offered to the outside world, while theoretical frameworks are rather directed towards research. Moreover, the choice of a theoretical orientation by a team is well documented, whereas the team's vision of the empirical settings is not explicit. Even the level at which these settings are to be considered (local, national or global) is not discussed. It seems that the teams consider implicitly that their vision has universal value. The case of the DIDIREM team shows how this vision, far from being universal, is influenced by previous work in the particular context they created by articulating

\footnotetext{
${ }^{7} \mathrm{http}: / /$ casyopee.eu
} 
the local level of the relationship with teachers, the national level of research and experimentation in the French context and the global level of international research.

Elucidating the relationship between contextual characteristics and research outcomes like scenarios and participants' behavior interpretation in the teaching experiments was less obvious. At first view, the theoretical frameworks seem to have the main influence, but they cannot be considered in isolation. In the DIDIREM case, implementing the teaching experiment depended much on the possibility of merging the researchers' theoretical orientations with the teachers' views influenced by considerations about the curriculum and about outcomes to share with colleagues. Then contextual characteristics and their effects cannot be analyzed in isolation, but rather appear to be entangled into a complexity where research activity takes place with a direct influence on research outcomes. In consequence we do not offer universal answers but rather tools for addressing specific cases. Particularizing to the DIDIREM example, the cross-studies helped the team to enlarge its view and initiated a common work between researchers and teachers opening new prospects for the teaching of functions with technology. The team identified contextual characteristics in the settings it was working in, offering potentialities of evolution resulting in re-contextualization of modalities of employment both of Casyopée and of Cruislet issued from other teams' contexts. The most important feature in the cross-studies seems to be the opportunity it provides to become familiar with another team's context and to question its own context. This is far from trivial, first because as demonstrated above, these views are not explicit and even not conscious, and second because it is more comfortable to stick to one's unquestioned context.

With regard to methods for working against contextual limits we distinguish between the two phases of a cross-study. Cross-experimentation draws attention to contextual characteristics at the global level of theoretical frameworks and dominant culture. This could be already conjectured after the trial cross-experimentations in TELMA (Kynigos \& Psycharis, 2009). What appears here is that cross-experimenting does not really question the complex web of conceptual characteristics idiosyncratic to each team. In contrast, cross-analysis helps the team to reconsider its context, identifying contextual characteristics offering opportunities for a change and then performing successful re-contextualization.

We conclude this paper with three prospective remarks.

First, we insisted on the necessity of a re-contextualization of research outcomes, that is to say the construction of a new context where these outcomes make sense. The researchers' task is then not to try to present new knowledge in a de-contextualised way, or to acknowledge for limitations resulting of contextual characteristics. The task is to work in common in order that outcomes of a research study emerged in some settings might be insightful in other settings. Cross-case analysis was in ReMath the method for working together. We do not pretend that this method can apply to any domain of study, but, after the ReMath experience, there is evidence that re-contextualization requires deep awareness of contexts and then special methods to get this awareness.

Second, in the ReMath case presented above, frameworks are important characteristics in the academic settings, and can also be seen as research outcomes. However, if recontextualization were limited to frameworks, it would be only another way of networking theories within the academic settings. The case of DIDIREM shows that re-contextualization can go deeper so as to involve the empirical settings: finding opportunities for evolution by working with teachers at the border of the two settings.

And finally, this approach of re-contextualization was done in the special case of a research project about innovative software and with a special method of cross-analysis. For us, the software was very important as boundary object embedding mostly implicit contextual 
characteristics. As the Cruislet case shows, the task of implementing a "real life" classroom scenario with "alien" software is not easy, and at the beginning is not rewarding. As the Casyopée case shows, it is also not easy for a team designing a piece of software, to look at another team implementing a scenario with this software and to try to benefit from this implementation. Both experiences imply deep reconsideration of often implicit choices that was possible thanks to the common work in the cross-case study. We must however recognize that it was time and effort consuming, and then possible only thanks to a European research project. The question is then open of other possible boundary objects and methods of common work for effective re-contextualization.

\section{References}

Artigue, M. (coord.) (2009). Integrative Theoretical Framework-Version C. Deliverable 18, ReMath Project. www.remath.cti.gr

Artigue, M. (2002). Learning mathematics in a CAS environment: the genesis of a reflection about instrumentation and the dialectics between technical and conceptual work. International Journal of Computers for Mathematics Learning, 7(3), 245-274.

Bartolini Bussi, M. G., \& Mariotti, M. A. (2008). Semiotic mediation in the mathematics classroom: Artifacts and signs after a Vygotskian perspective. In L. English, M. Bartolini Bussi, G.Jones, R. Lesh, \& D. Tirosh (Eds.), Handbook of international research in mathematics education (second revised edition, pp. 746-783). Mahwah: Lawrence Erlbaum.

Bottino, R.M., \& Kynigos, C. (2009). Mathematics education \& digital technologies: facing the challenge of networking European research teams, International Journal of Computers for Mathematical Learning. Kluwer Academic Publishers, Netherlands, 14(3), 203-215.

Brousseau, G. (1997). The theory of didactic situations in mathematics. Dortrecht: Kluwer Academic Publishers.

Cerulli, M., Trgalová, J., Marraci, M., Psycharis, G. , \& Georget, J.-P. (2008). Comparing theoretical frameworks enacted in experimental research: TELMA experience. Zentralblatt fur Didaktik der Mathematik, 40(2), 201-213.

Chevallard, Y. (1999). L'analyse des pratiques enseignantes en théorie anthropologique du didactique. Recherches en didactique des mathématiques, 19(2), 221-266.

Cobb, P., \& Yackel, E. (1996). Constructivist, emergent and sociocultural perspectives in the context of developmental research. Journal of Educational Psychology, 31, 175-190.

Cuoco, A. (2002). Thoughts on reading Artigue's "Learning mathematics in a CAS environment." International Journal of Computers for Mathematical Learning, 7(3), 293-299.

Engeström, Y. (1987). Learning by expanding : an activity-theorical approach to developmental research. Helsinki, Orienta-Konsulit.

Gallou-Dumiel, E. (1987). Symétrie orthogonale et micro-ordinateur, Recherches en didactique des mathématiques, 8 (1-2),5-59.

Guin, D., \& Trouche, L. (1999). The Complex Process of Converting Tools into Mathematical Instruments: the case of calculators. International Journal of Computers for Mathematics Learning, 3(3), 195-227.

Healy, L. , \& Kynigos, C. (2010) Charting the microworld territory over time: design and construction in learning, teaching and developing mathematics The International Journal of Mathematics Education, ZDM 42. 63-76.

Jackiw, N. (2010) Attention to detail; broadening our design language. In Chapter 21, C. Hoyles \& J. B. Lagrange (eds.) Mathematics Education and Technology: Rethinking the Terrain (pp. 431-433). New York: Springer. 
Kahane, J. (coord.) (2002) L'enseignement des sciences mathématiques. Centre National de Documentation Pédagogique, Odile Jacob, Paris.

Kafai, Y. , \& Resnick, M., Eds. (1996) Constructionism in practice. Designing, thinking and learning in a digital world, Lawrence Earlbaum Associates, New Jersey.

Kieran, C. , \& Drijvers, P. (2007). The Co-Emergence of Machine Techniques, Paper-andPencil Techniques, and Theoretical Reflection: A Study of CAS use in Secondary School Algebra. International Journal of Computers for Mathematical Learning, 11 (2), 205-263.

Kieran, C. (2007). Learning and teaching algebra at the middle school through college levels. In Lester, (Ed.), Second handbook of research on mathematics teaching and learning (pp. 707-762). Greenwich, CT: Information Age Publishing.

Kieran, C. (2004). The Core of Algebra: Reflections on its main activities. In K. Staceyet al. (Eds.), The Future of Teaching and Learning of Algebra: 12th ICMI Study (pp.21-24). Kluwer: Dordrecht.

Kynigos, C. (2012) Constructionism: theory of learning or theory of design? Regular Lecture, Proceedigns of the 12th International Congress on Mathematical Education, Seoul, S. Korea.

Kynigos, C. , \& Psycharis, G. (2013). Designing for instrumentalisation: Constructionist perspectives on instrumental theory. International Journal for Technology in Mathematics Education, 20(1), 15-20.

Kynigos, C. , \& Psycharis, G. (2009) The role of context in research involving the design and use of digital media for the learning of mathematics: boundary objects as vehicles for integration, International Journal of Computers for Mathematical Learning, 14(3), 265298.

Laborde C. (2001) Integration of technology in the design of geometry tasks with Cabrigeometry. International Journal of Computers for Mathematical Learning, 6, 283-317.

Lagrange J.B. (2013) Analyzing teacher classroom use of technology: Anthropological Approach and Activity Theory. International Journal for Technology in Mathematics Education, 20(1), 33-37.

Lagrange, J.-B. , \& Artigue, M. (2009). Students' activities about functions at upper secondary level: a grid for designing a digital environment and analysing uses. In $\mathrm{M}$. Tzekaki, M. Kaldrimidou \& C. Sakonidis (Eds.), Proceedings of the 33rd Conference of the International Group for the Psychology of Mathematics Education (Vol. 3, pp. 465472). Thessaloniki, Greece: PME.

Lagrange, J. B. (2005). Curriculum, classroom practices, and tool design in the learning of functions through technology-aided experimental approaches. International Journal of Computers for Mathematical Learning, 10, 143-189.

Lagrange, J.B. (1999). Complex calculators in the classroom: theoretical and practical reflections on teaching precalculus. International Journal of Computers for Mathematical Learning, 4(1), 51-81.

Lagrange J.B. (2000). L'intégration d'instruments informatiques dans l'enseignement: Une approche par les techniques. Educational Studies in Mathematics, 43(1),1-30.

Le Feuvre, B., Meyrier, X. , \& Lagrange, J.B. (2010) Apprendre des notions mathématiques, géographiques et algorithmiques à l'aide d'un environnement de navigation 3D audessus de la Grèce. Repères IREM, 81, 29-48.

Lave, J. (1988). Cognition in practice. Cambridge: Cambridge University Press.

Nunes, T., Schliemann, A. D., \& Carraher, D. W. (1993). Street mathematics and school mathematics. Cambridge: Cambridge University Press. 
Maracci, M. ,Cazes, C. , Vandebrouck, F. , \& Mariotti, M. A. (2013). Synergies between theoretical approaches to mathematics education with technology: a case study through a cross-analysis methodology, Educational Studies in Mathematics, 84(3), 461-485.

Markopoulos, C., Kynigos, C., Alexopoulou , \& E. Koukiou, A. (2009) Mathematisations while navigating with a geo-mathematical microworld, In M. Tzekaki, M. Kaldrimidou \& C. Sakonidis (Eds.), Proceedings of the 33rd Conference of the International Group for the Psychology of Mathematics Education (vol. 4, pp. 97-104). Thessaloniki, Greece: PME.

Minh, T. K. (2012). Learning about functions with the help of technology: students' instrumental genesis of a geometrical and symbolic environment. In T. Y. Tso (Ed.), Proceedings of the 36th Conference of the International Group for the Psychology of Mathematics Education (Vol. 3, pp. 217-224). Taipei, Taiwan: PME.

Monaghan, J. (2009). People and Theories. Proceedings of CERME 6, January 28th-February 1st 2009, Lyon France (C INRP $2010<$ www.inrp.fr/editions/cerme6>

Monaghan, J. (2005). Computer Algebra, Instrumentation and the Anthropological Approach International Journal for Technology in Mathematics Education, 14(2), 63-71.

Morgan, C., Mariotti, M. A., \& Maffei, L. (2009). Representation in computational environments: epistemological and social distance. International Journal of Computers for Mathematical Learning, 14(3), 241-263.

Papert, S. (2002). The turtle's long slow trip: macro-educological perspectives on microworlds. Journal of Educational Computing Research, 27(1), 7-28.

Rachlin, S. (1989). The research agenda in algebra: a curriculum development perspective. In Kieran and Wagner (eds) Research Issues in the Learning and Teaching of Algebra (pp. 257-265). NCTM-LEA.

Sriraman, B., \& English, L. (eds) (2010).Theories of Mathematics Education: Seeking New Frontiers. Springer Science, Berlin/Heidelberg.

Steffe, L. P., \& Thompson, P. W. (2000). Teaching experiment methodology: Underlying principles and essential elements. In R. Lesh \& A. E. Kelly (Eds.), Research design in mathematics and science education (pp. 267-307). Hillsdale, NJ: Erlbaum.

Tall, D. (1996). Functions and calculus. In Bishop A.J. et al. (eds.) International Handbook of Mathematics Education (pp. 289-325). Dordrecht: Kluwer.

Van Oers, B. (1998). From context to contextualizing. Learning and Instruction,8(6), 473488.

Verillon, P. , \& Rabardel, P. (1995). Cognition and artifacts: a contribution to the study of thought in relation to instrumented activity. European Journal of Psychology of Education, 9 (3), 77-101.

Yackel, E. , \& Cobb, P. (1996). Sociomathematical norms, argumentation, and autonomy in mathematics. Journal for Research in Mathematics Education, 27(4), 458-477. 